\title{
Peningkatan Sumber Daya Manusia Melalui Pelatihan Dan Pendampingan Digital Marketing
}

\author{
Nanto Purnomo \\ Universitas Islam Lamongan, Indonesia \\ Email: nantopurnomo@unisla.ac.id
}

\begin{abstract}
ABSTRAK
Tujuan dalam kegiatan pelatihan dan pendampingan digital marketing ini untuk meningkatkan pengetahuan, kemampuan dan keterampilan peserta dalam hal pemanfaatan platform digital. Serta memberikan alternatif pilihan mata pencaharian peserta atau sumber baru untuk meningkatkan pendapatannya.Sasaran pelatihan dan pendampingan merupakan remaja generasi milenial yang berusia 15 - 24 tahun desa Maor kecamatan kembangbahu dengan jumlah orang 15 peserta yang seluruhnya memiliki handphone yang mendukung aplikasi digital marketing.Metode yang digunakan dalam pelatihan dan pendampingan digital marketing adalah metode ceramah atau sosialisasi dan praktik langsung. Dari pelatihan digital marketing dapat disimpulkan bahwa motivasi sangat penting untuk membangun dan dapat memberikan semangat terhadap peserta pelatihan dalam berwirausaha. Dari kegiatan pelatihan dan pendampingan ini di hasilkan 15 akun yang dapat menjadi alat atau sarana digital marketing. Selain itu juga terbentuk sharing group yang berguna untuk wadah penyemangat serta membangun ikatan persaudaraan, kekompakan antar peserta dan sharing masalahmasalah yang dihadapi serta solusi yang bisa di diskusikan bersama antar peserta pelatihan dan pendampingan digital marketing. Dengan adanya pelatihan dan pendampingan digital marketing ini semoga bermanfaat dan dapat meningkatkan pengetahuan, kemampuan dan keterampilan dalam hal digital marketing.
\end{abstract}

Kata kunci : wirausaha, sumber daya manusia dan digital marketing

\section{PENDAHULUAN}

Faktor Pandemi covid -19 tidak dapat di pungkiri merupakan salah satu penyebab terjadinya pengangguran di indonesia. Sebagaimana data BPS yang menyatakan bahwa per agustus 2020 Tingkat pengangguran terbuka (TPT) sebesar 7,07 persen, meningkat 1,84 persen poin dibandingkan dengan Agustus 2019. Terdapat 29,12 juta orang (14,28 persen) penduduk usia kerja yang terdampak Covid-19, terdiri dari pengangguran karena Covid-19 (2,56 juta orang), Bukan Angkatan Kerja (BAK) karena Covid-19 (0,76 juta orang), sementara tidak bekerja karena Covid-19 (1,77 juta orang), dan penduduk bekerja yang mengalami pengurangan jam kerja karena Covid-19 (24,03 juta orang). Data BPS Agustus 2020.

Data BPS mengatakan Lapangan pekerjaan yang mengalami peningkatan persentase terbesar adalah Sektor Pertanian (2,23 persen poin). Sementara sektor yang mengalami penurunan terbesar yaitu Sektor Industri Pengolahan (1,30 persen poin). Di lihat dari hal tersebut banyak sekali masyarakat desa yang terpaksa kembali bekerja ke ladang untuk menyambung hidupnya. Sedangkan sektor pertanian sangat tergantungan dengan musim. Musim yang tak menentu akibat dari Global warming dapat menyebabkan ketidakpastian dan 
kerugian tersendiri di sektor pertanian. Peneliti melihat lapangan kerja di indonesia akan semakin sempit sedangkan pengangguran makin tinggi.

Maka dari itu di perlukannya peningkatan sumber daya manusia dalam bentuk pelatihan digital marketing dalam upaya memberikan harapan dan alternatif mata pencarian baru di masa pandemi ini.

Tabel

tingkat pengangguran terbuka berdasarkan kelompok umur

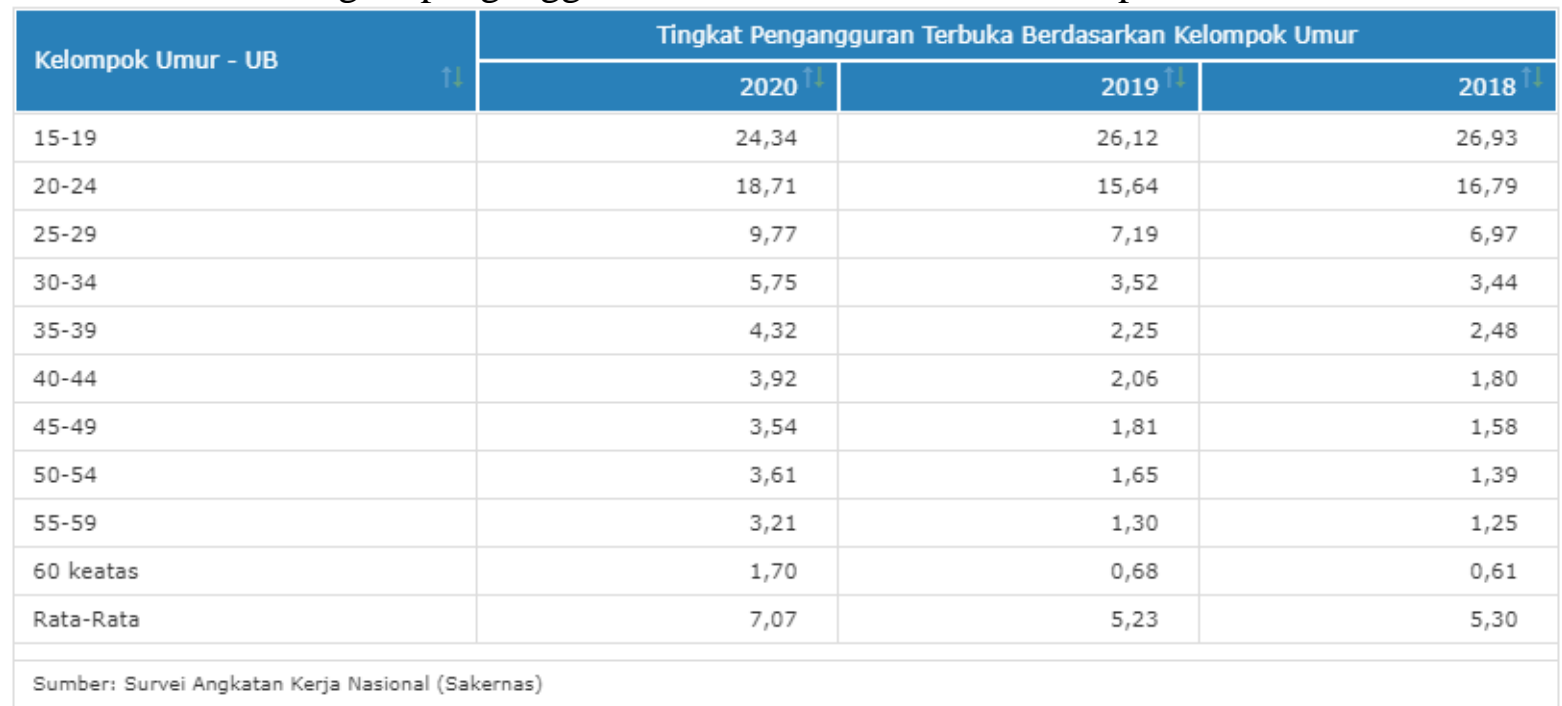

Melihat data BPS angka tingkat pengangguran terbuka berdasarkan kelompok umur adalah pada usia 15-19 tahun yakni sebesar 24,34 \% di tahun 2020. Maka dari itu sasaran pelatihan ini di prioritaskan untuk para remaja di desa. Tujuan kegiatan pengabdian ini untuk meningkatkan kemampuan dan pengetahuan pemasaran secara digital dengan memanfaatkan platform yang telah ada seperti shopee, facebook dan WhatsApp.Dengan ada nya kegiatan ini menjadikan para peserta menguasai digital marketing, sehingga dapat membantu memberikan opsi alternatif mata pencarian dan dapat menjadi alternatif sumber pemasukan dan peningkatan perekonomian dimasa yang akan datang.

\section{Tinjauan wirausaha}

Sumber daya manusia yang berkualitas akan menentukan produktivitas kerja yang dibutuhkan dalam setiap bidang pekerjaan. Salah satunya adalah wirausaha. Menumbuhkan minat berwirausahatidaklah mudah apalagi seorang wirausahawan yang masih remaja. Remaja adalah usia dimana seorang yang lebih cenderung memiliki emosi yang labil. Kunci sukses untuk menumbuhkan minat wirausaha remaja adalah faktor yang mendorong dari dalam. faktor yang dapat mendorong keputusan menjadi wirausahawan adalah memiliki toleransi terhadap risiko, memiliki kebebasan dalam bekerja tidak dibatasi oleh waktu dan optimisme untuk keberhasilan dirinya. ( Purnomo and Muhtarom 2018 ).

Untuk mengembangakan karakter, sikap, pengetahuan dan keterampilan tersebut dapat di bentuk dengan usaha langsung dan tidak langsung sehingga menghasilkan kualitas sumber daya manusia yang baik. pelatihan dan pendampingan merupakan alternative solusi dalam peningkatan sumber daya manusia.

Penelitian ini menunjukkan bahwa dampak pengelolaan dari digital marketing pada start - up memang meningkatkan pendapatan start - up namun karena kurangnya 
kemampuan menyediakan konten dan merespon cepat atas konten - konten yang sudah disediakan menjadikan para wirausaha baru (start- up) belum mendapatkan hasil maksimal dari pengelolaan digital marketing tersebut. (aliami, dkk;2018)

\section{Digital marketing}

Philip Kotler (2007:5) mendefinisikan bahwa, " Pemasaran adalah suatu proses sosial dan manajerial yang membuat individu dan kelompok memperoleh apa yang mereka butuhkan serta inginkan lewat penciptaan dan pertukaran timbal balik produk dan nilai dengan orang lain."

Digital marketing adalah upaya pemasaran produk dengan menggunakan media digital dan jaringan internet. Banyak kelebihan digital marketing dibandingkan upaya pemasaran tradisional. Kelebihan tersebut adalah kemudahan dalam menjangkau target pasar lebih luas, membutuhkan biaya yang lebih kecil dan menggunakan komunikasi dua arah dengan calon konsumen.

digital marketing Menurut Urban (2004:2) adalah menggunakan internet dan teknologi informasi untuk memperluas dan meningkatkan fungsi marketing tradisional. Strategi digital marketing atau pemasaran online saat ini sangat penting dilakukan dan dapat diyakini lebih efektif serta efisien untuk menjangkau target pasar yang diinginkan. Penelitian Pradiani (2018) pun sudah membuktikan bahwa pemasaran secara online memang dapat meningkatkan hasil penjualan produk karena sekarang ini, masyarakat cenderung lebih suka mencari referensi secara online bahkan membeli produk secara online. Pemasaran secara online juga dapat meningkatkan jangkauan pemasaran yang tidak dapat atau susah dijangkau oleh pemasaran offline (Febriyantoro \& Arisandi, 2018).

Namun pemasaran digital bukan tentang memahami teknologi yang mendasarinya, melainkan tentang memahami orang, bagaimana mereka menggunakan teknologi itu, dan bagaimana memanfaatkan teknologi untuk terlibat dengan mereka secara lebih efektif, dan harus lebih didorong oleh kualitas komunikasi daripada kuantitasnya (Taiminen \& Karjaluoto, 2014 ).

Beberapa upaya telah dilakukan untuk meningkatkan keterampilanpemasar dalam digital marketing. Pelatihan untuk meningkatkan keterampilan dan pengetahuan pemasar telah memiliki efek positif. Melalui workshop digital marketing (penyampaian materi, diskusi dan praktik) maka pemasar lebih memahami pentingnya penggunaan media internet untuk meningkatkan daya saing usahanya (Baladraf dkk, 2018 ).

\section{METODE PELAKSANAAN}

Pelatihan dan pendampingan ini diselenggarakan pada bulan Oktober 2020 di desa maor kecamatan kembangbahu. Sasaran pelatihan dan pendampingan merupakan remaja generasi milenial yang berusia 15 - 24 tahun desa Maor kecamatan kembangbahu dengan jumlah orang 15 peserta yang seluruhnya memiliki handphone yang mendukung aplikasi digital marketing.

\section{Pelatihan}

Dalam pelatihan digital marketing ini menggunakan metode ceramah atau sosialisasi. Pada pelatihan digital marketing ini para remaja di bekali pengetahuan tentang kewirausahaan untuk memotivasi serta menumbuhkan minat dan pembentukan karakter wirausahawan. Selain itu juga tidak lupa para remaja dibekali ilmu pengetahuan terkai isu-isu teknologi informasi yang positif tentang penggunaan digital marketing, sehingga mereka paham dan lebih bijak dalam 
menggunakan platform digital ini. Platform tersebut ialah sosial media seperti facebook, instagram dan Watsapp, serta marketplace seperti shopee dan tokopedia.

\section{Pendampingan}

Dalam pendampingan digital marketing ini menggunakan metode praktek langsung dan di dampingi dalam pembuatan akun digital marketing. Selain pembuatan akun para peserta juga dibekali pengetahuan kegunaan fitur-fitur, bagaimana cara berjualan di platform digital serta tips dan trik dalam berjualan online.

\section{HASIL DAN PEMBAHASAN}

Para peserta pelatihan digital marketing mendapatkan pengetahuan dan wawasan baru tentang kewirausahaan. Terdapat perbedaan minat yang masih kurang di beberapa peserta pelatihan tentang berwirausaha. Ini dikarenakan terdapat perbedaan usia diantara peserta pelatihan. Peserta yang lebih muda cenderung pesimis dan takut gagal dalam berwirausaha. Maka dengan itu peserta diberikan motivasi-motivasi serta pengetahuan tentang toleransi terhadap resiko sehingga dapat menumbuhkan semangat para peserta kembali. Sebagaimana penelitian ( purnomo and muhtarom(2018) yang menyatakan bahwa toleransi terhadap resiko memiliki pengaruh yang signifikan terhadap minat untuk berwirausaha. Untuk peserta yang lebih matang yaitu peserta yang sudah lulus pendidikan sekolah menengah atas (SMA) ada beberapa yang sudah pernah berjualan online platform yang digunakan adalah facebook dan watsapp dengan lingkup pemasaran antar temannya sendiri satu desa. Sistem online shop yang di gunakan adalah pre- orde. Hal ini menarik narasumber, ternyata ada beberapa peserta yang sudah terjun di dunia digital marketing, sehingga dapat dijadikan penyemangat dan leader project untuk para peserta lainnya yang belum terjun ke dunia digital marketing.

Mengingat kembali usia para peserta antara 15 - 24 tahun, di usia-usia ini peserta memiliki tingkat emosional yang belum cukup stabil. Dunia digital bagaikan tombak bersisi dua yang memiliki dampak positif dan negatif. Untuk meminimalkan dampak negatif digital terutama sosial media para peserta di bekali pengetahuan dan wawasan -wawasan isu-isu terkini teknologi informasi sehingga di harapkan para peserta mampu menggunakan teknologi informasi dengan baik dan lebih bijak.

Dalam pelatihan ini para peserta juga dikenalkan dengan beberapa platform yang dapat digunakan sebagai sarana atau alat dalam praktek digital marketing, diantaranya media sosial dan marketplace. Media sosial yang dimaksud dalam pelatihan ini meliputifacebook, instagram dan Watsapp. Dan marketplace yang dimaksud dalam pelatihan ini adalah shopee dan tokopedia.

Dalam pendampingan digital marketing para peserta lebih diarahkan untuk praktek langsung dalam pembuatan akun digital marketing seperti facebook, shopee dan tokopedia. Selain pembuatan akun para peserta juga di bekali pengetahuan kegunaan fitur-fitur dan sistem pemasaran seperti pre-order, COD (Cash On Delivery) serta online shop. Para peserta juga didampingi bagaimana cara berjualan di platform digital. Mulai dari upload produk, bagaimana membuat promosi, menerima pesanan, packing, pengiriman barang, pencairan saldo di marketplace (shopee dan tokopedia) serta bagaimana menghadapi kompline pelanggan. Untuk meningkatkan kinerja platform yang di buat mereka juga di bekali tips dan trik dalam berjualan online. Tips dan trik Agar Barang Cepat Laku di Marketplace sebagai berikut : 
- Berikan deskripsi yang jelas dan lengkap, agar pembeli merasa yakin dengan produk Anda.

- Riset dahulu harga pasar sebelum menentukan harga produk.

- Jangan lupa melengkapi lapak dengan foto produk yang sebenarnya.

- Respon penanya sebaik mungkin.

- Manfaatkan fitur yang ditawarkan oleh Facebook, seperti fitur berbagi ke group-group facebook.

Untuk mempertahankan keberlanjutan program maka setelah pendampingan usai di buatkan group Watsapp. Sharing group ini berguna untuk wadah penyemangat serta membangun ikatan persaudaraan, kekompakan antar peserta dan sharing masalah-masalah yang dihadapi serta solusi yang bisa di diskusikan bersama antar peserta pelatihan dan pendampingan digital marketing.

\section{KESIMPULAN DAN SARAN}

Dari pelatihan digital marketing dapat disimpulkan bahwa motivasi sangat penting untuk membangun dan dapat memberikan semangat terhadap peserta pelatihan dalam berwirausaha. Dari kegiatan pelatihan dan pendampingan ini di hasilkan 15 akun yang dapat menjadi alat atau sarana digital marketing sebagai awal untuk membangun dan alternatif pilihan mata pencaharian bagi peserta pelatihan. Selain itu juga terbentuk sharing group yang berguna untuk wadah penyemangat serta membangun ikatan persaudaraan, kekompakan antar peserta dan sharing masalah-masalah yang dihadapi serta solusi yang bisa di diskusikan bersama antar peserta pelatihan dan pendampingan digital marketing. Dengan adanya pelatihan dan pendampingan digital marketing ini semoga bermanfaat dan dapat meningkatkan pengetahuan, kemampuan dan keterampilan dalam hal digital marketing. Kedepan narasumber berharap peserta pelatihan dan pendampingan digital marketing ini semakin meningkat sehingga dapat memberikan kesempatan kepada masyarakat desa maor kecamatan kembangbahu untuk meningkatkan pengetahuan, kemampuan dan keterampilannya dalam hal pemanfaatan platform digital.

\section{DAFTAR PUSTAKA}

Aliami, sri.,dkk(2018). Dampak Pengembangan Pemasaran Digital Pada Startup's (Studi

Kasus Pada Wirausaha Baru). Jurnal Ekonomi Universitas Kadiri. Vol 3 no 1 . 73-87

Baladraf, M.I.F., Sembodo, G., Hasanah, L.U \& Pramono. A. (2018). Pelatihan Sukses

Berbisnis Online Memajukan Perekonomian Masyarakat Melalui Pemasaran Online

Putat Jaya Surabaya. Jurnal Abdikarya : Jurnal Karya Pengabdian Dosen dan

Mahasiswa, Februari 2018 Vol 01 No 1

Febriyantoro, M. T., \& Arisandi, D. (2018). Pemanfaatan Digital Marketing Bagi

Usaha Mikro, Kecil Dan Menengah Pada Era Masyarakat Ekonomi Asean. JMD:

Jurnal Riset Manajemen \& Bisnis Dewantara, 1(2), 61-76.

https://doi.org/10.26533/jmd.v1i2.175

Kotler, Philip. 2008. Manajemen Pemasaran Edisi 12 Jilid 2. Jakarta: Indeks Kotler 2008

Pradiani, T. (2018). Pengaruh Sistem Pemasaran Digital Marketing Terhadap

Peningkatan Volume Penjualan Hasil Industri Rumahan. Jurnal Ilmiah Bisnis

Dan Ekonomi Asia, 11(2), 46-53. https://doi.org/10.32812/jibeka.v11i2.45 
Purnomo, Nanto and Abid Muhtarom. 2018. "Determination Factor Alumni and Student of Economic Faculty Lamongan Islamic University to Become Enterpreneur." AKUISISI14(1):19-25.

Syairozi, M. I., \& Wijaya, K. (2020, October). MIGRASI TENAGA KERJA INFORMAL: STUDI PADA KECAMATAN SUKOREJO KABUPATEN PASURUAN. In Seminar Nasional Sistem Informasi (SENASIF) (Vol. 4, No. 1, pp. 2383-2394).

Taiminen, H.M \& Karjaluoto, H (2014). The usage of digital marketing channels in SMEs. Journal of Small Business and Enterprise Development Vol. 22 No. 4, 2015 pp. 633651

Urban, Glen (2004) Digital Marketing Strategy.Pearson Educattion, Upper Saddie River, New Jersey. USA 